\title{
General Psychiatry Unmet needs for mental care services for older people in Bangladesh during the COVID-19 pandemic
}

\author{
Md Sazedur Rahman (D) , ${ }^{1}$ Md Ashfikur Rahman, ${ }^{2}$ Laila Afroze, ${ }^{1}$ \\ Sheikh Mohammed Shariful Islam (i) ${ }^{3}$
}

To cite: Rahman MS,

Rahman MA, Afroze L, et al. Unmet needs for mental care services for older people in Bangladesh during the COVID-19 pandemic. General Psychiatry 2020;33:e100294. doi:10.1136/ gpsych-2020-100294

Received 30 May 2020 Revised 19 August 2020 Accepted 04 September 2020

Check for updates

(c) Author(s) (or their employer(s)) 2020. Re-use permitted under CC BY-NC. No commercial re-use. See rights and permissions. Published by BMJ.

${ }^{1}$ Statistics Discipline, Khulna University, Khulna, Bangladesh ${ }^{2}$ Development Studies Discipline, Khulna University, Khulna, Bangladesh

${ }^{3}$ Institute for Physical Activity and Nutrition, School of Exercise and Nutrition Sciences, Faculty of Health, Deakin University, Burwood, Victoria, Australia

Correspondence to Mr Md Sazedur Rahman; sazedur.stat@gmail.com

\section{Dear Editor}

We read with interest the editorial by Qiu et $a l^{1}$ about the psychological distress among the general population in China during the COVID-19 pandemic and policy recommendations. The elderly are more vulnerable to increased mental health problems during COVID-19, which has raised significant challenges for community mental health services. ${ }^{12}$ Older people with comorbid conditions, including cardiovascular diseases, lung diseases, diabetes and hypertension are more likely to be severely affected and die because of COVID-19, which is caused by SARS-CoV-2. ${ }^{3}$

Bangladesh is one of the most densely populated countries in the world, making it more vulnerable to the rapidly spreading COVID-19. As of 28 May 2020, 38292 cases of COVID-19 have been confirmed in Bangladesh, including 501 deaths. ${ }^{4}$ Although only $8 \%$ of the total patients with COVID-19 were elderly persons (aged $>60$ years), they account for almost $42 \%$ of total deaths. ${ }^{4}$ In 2015 , there were 12.5 million $(7.5 \%$ of the total population) older people (aged $\geq 60$ years) in Bangladesh. ${ }^{5}$ However, the proportion of older people is almost $5 \%$ lower than the overall ratio of geriatric people worldwide (ie, about $12.5 \%$ or 901 million people globally were aged 60 years or above in 2015). ${ }^{6}$ Among the older people in Bangladesh, around $53.8 \%$ have multicomorbidities, ${ }^{5}$ making them more vulnerable to the COVID-19 infection.

As SARS-CoV-2 has high transmissibility and is mainly transmitted from person to person, ${ }^{3}$ to prevent the aggressive and rapid outbreak of the pandemic, the Government of Bangladesh has advised people to stay at home. Therefore, during the COVID-19 outbreak, older people are suffering from lack of social contacts and physical activities.
The lack of social connections and the overall situation of the pandemic, including the rapid transmission of SARS-CoV-2 and high death rate, can result in combined effects of fear, stress, anxiety, depression and mood disorders in older people, which can be overwhelming and cause strong emotions. ${ }^{17-10}$ The sedentary lifestyle, idleness and physical inactivity might increase the prevalence and severity of obesity, diabetes, stroke and hypertension in aged people, which can lead to severe disabilities, deformities, functional incapacity and social rejection. ${ }^{11}$ However, the COVID-19 pandemic has posed significant challenges for healthcare services throughout the world, including Bangladesh. The number of hospital admissions has dramatically increased, and many people in the community are facing challenges in seeking both emergency and primary healthcare services, as the public health system has already been overburdened with patients with COVID-19. Moreover, healthcare professionals on the front line are at increased risk of being infected with COVID-19, and they are also highly vulnerable to physical and mental health problems, which may affect their services. ${ }^{7}$ Besides, older people in the community may avoid inpatient and outpatient services due to fear of infection, which can increase the severity of the diseases.

Mental disorders are highly prevalent in Bangladesh. Recent studies have reported a higher prevalence $(55.5 \%)$ of geriatric depressive symptoms in Bangladesh. ${ }^{12}$ During the epidemic, people with a mental health problem may be at a higher risk from social isolation. $^{1} 213$ Recent continuous media coverage and reports of older adults being prone to infection and dying because of COVID-19, forecasting of economic recessions and a possible famine have resulted in increased psychological and mental pressure 
among older people. ${ }^{13}$ This might lead to increased psychological and mental health problems in the older age group in Bangladesh. People with psychiatric disorders may face more difficulties in dealing with the COVID-19 situation.

Current approaches to COVID-19 prevention include wearing masks; avoiding close contacts; frequent hand washing; avoiding touching the eyes, nose or mouth with unwashed hands; avoiding handshakes, which might increase the risk of infection. However, older people with severe comorbid conditions (ie, strokes), mental disorders (ie, dementia), advanced age, who are uneducated, lack information, awareness or self-protection skills might face more difficulties in applying these skills to combat COVID-19. Therefore, for the well-being of these older adults, there is a need for additional care and mental support. Mental health remains highly neglected by the health planners and policy-makers in Bangladesh, with only 0.073 psychiatrists per 100000 population. ${ }^{14}$ As the COVID-19 pandemic is overwhelming, healthcare services, healthcare professionals and the geriatric mental health services are facing significant challenges. ${ }^{7-9} 15$ To this an effective alternative are public health services that provide essential mental health services. ${ }^{7-9} 16$ Telemedicine or online healthcare services for older people can be an effective alternative way of providing health services, like in China, while still keeping social distance. ${ }^{17-9} 16$ However, Bangladeshi older adults have limited access to the internet and the ability to avail such services. Therefore, mass media, mainly television, can play a proactive role by telecasting special mental health programmes for aged people. However, currently, most of the television programmes and social media has not provided any such services. Therefore, appropriate mental health programmes, including motivational and educational programmes, need to be provided for the older people in Bangladesh during, and post, this COVID-19 epidemic. Moreover, telemedicine or online healthcare services can also be helpful for people who have access to the internet and relevant services (eg, smartphones, computers and technical knowledge to use it). ${ }^{17-9} 16$

Additionally, family support can play a significant role in the physical and mental well-being of older people during the COVID-19 pandemic. A previous study showed that family support was significantly associated with a decreased level of depressive symptoms. ${ }^{17}$ Therefore, there is an urgent need for emotional and practical support from family members, including children of older people. Traditionally, older people used to live with their male offspring and depended on them for all their needs. ${ }^{18} 19$ Additionally, they were highly respected and enjoyed a prime position in the family. But, because of modernisation and urbanisation, the traditional joint families have started splitting into nuclear or small-size families, and at the same time, the position of the older people has changed, and elder abuse has increased severely. ${ }^{1819}$ At present, with limited senior care homes in Bangladesh, most older people live alone or with their older partners or their children. ${ }^{5}$ However, in the grievous situation of COVID-19, the family members should be more dutiful and careful and regularly contact older people through phone calls if they do not live together. For the psychological and physical well-being of older people, these practices are also recommended after the epidemic is over. However, family members or caregivers of older people may have limited knowledge about mental health support, which is another concern; therefore, effective programmes to learn about providing such support is also needed. In Bangladesh, experts providing emergency education programmes about mental health support to the older people through mass media, such as television, newspaper and radio, and through social media, such as Facebook and Youtube channels, would be fruitful.

In summary, older people are more susceptible to psychological problems during the COVID-19 outbreak. Specialised mental health programmes through television, effective telemedicine services and adequate family support can play a proactive role in the mental and physical well-being of older people in Bangladesh and elsewhere during, as well as after, the pandemic.

\section{Twitter Sheikh Mohammed Shariful Islam @drsislam}

Contributors MSR and SMSI: conceptualisation, writing original draft, writingreview and editing. MAR and LA: writing original draft. All the authors have read and approved the final version for publication.

Funding The authors have not declared a specific grant for this research from any funding agency in the public, commercial or not-for-profit sectors.

Competing interests None declared.

Patient consent for publication Not required.

Provenance and peer review Not commissioned; externally peer reviewed.

Open access This is an open access article distributed in accordance with the Creative Commons Attribution Non Commercial (CC BY-NC 4.0) license, which permits others to distribute, remix, adapt, build upon this work non-commercially, and license their derivative works on different terms, provided the original work is properly cited, appropriate credit is given, any changes made indicated, and the use is non-commercial. See: http://creativecommons.org/licenses/by-nc/4.0/.

ORCID iDs

Md Sazedur Rahman http://orcid.org/0000-0003-1851-9233

Sheikh Mohammed Shariful Islam http://orcid.org/0000-0001-7926-9368

\section{REFERENCES}

1 Qiu J, Shen B, Zhao M, et al. A nationwide survey of psychological distress among Chinese people in the COVID-19 epidemic: implications and policy recommendations. Gen Psychiatr 2020;33:e100213.

2 Li S, Zhang Y. Mental healthcare for psychiatric inpatients during the COVID-19 epidemic. General Psychiatry 2020:33.

3 Zhou F, Yu T, Du R, et al. Clinical course and risk factors for mortality of adult inpatients with COVID-19 in Wuhan, China: a retrospective cohort study. Lancet 2020;395:1054-62.

4 Institute of Epidemiology, Disease Control and Research (IEDCR). Bangladesh Covid-19 update. Available: https://www.iedcr.gov.bd/ [Accessed 23 May 2020].

5 Bangladesh Bureau of Statistics (BBS). Elderly population in Bangladesh: current features and future perspectives. population monograph: Volume-4, 2015. Available: http://203.112.218.65:8008/ WebTestApplication/userfiles/Image/PopMonographs/elderlyFinal.pdf [Accessed 25 May 2020].

6 Nations U. World population ageing department of economic and social affairs. population division, 2015. Available: https://www. 
un.org/en/development/desa/population/publications/pdf/ageing/ WPA2015_Report.pdf [Accessed 21 Jul 2020].

7 Li W, Yang Y, Liu Z-H, et al. Progression of mental health services during the COVID-19 outbreak in China. Int J Biol Sci 2020;16:1732-8.

8 Yang Y, Li W, Zhang Q, et al. Mental health services for older adults in China during the COVID-19 outbreak. Lancet Psychiatry 2020;7:e19.

9 Xiang Y-T, Yang Y, Li W, et al. Timely mental health care for the 2019 novel coronavirus outbreak is urgently needed. Lancet Psychiatry 2020;7:228-9.

10 Coughlin SS. Anxiety and depression: linkages with viral diseases. Public Health Rev 2012;34:7.

11 Chakravarthy MV, Joyner MJ, Booth FW. An obligation for primary care physicians to prescribe physical activity to sedentary patients to reduce the risk of chronic health conditions. Mayo Clin Proc 2002;77:165-73.

12 Rahman MS, Rahman MA, Ali M, et al. Determinants of depressive symptoms among older people in Bangladesh. J Affect Disord 2020;264:157-62.
13 Douglas M, Katikireddi SV, Taulbut M, et al. Mitigating the wider health effects of covid-19 pandemic response. BMJ 2020;369:m1557.

14 Hossain MM, Hasan MT, Sultana A, et al. New mental health act in Bangladesh: unfinished agendas. Lancet Psychiatry 2019;6:e1.

15 Prvu Bettger J, Thoumi A, Marquevich V, et al. COVID-19: maintaining essential rehabilitation services across the care continuum. BMJ Glob Health 2020;5:e002670.

16 Liu S, Yang L, Zhang C, et al. Online mental health services in China during the COVID-19 outbreak. Lancet Psychiatry 2020;7:e17-18.

17 Li C, Jiang S, Zhang X. Intergenerational relationship, family social support, and depression among Chinese elderly: a structural equation modeling analysis. J Affect Disord 2019;248:73-80.

18 Rahman MS. Aging and negligence in Bangladesh. $J$ Gerontol Geriatr Res 2017;6:2.

19 Islam MN, Nath DC. A future journey to the elderly support in Bangladesh. J Anthropol Sci 2012;2012:1-6.

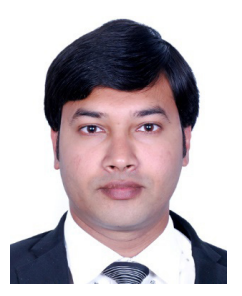

Sazedur Rahman completed his undergraduate and master's program in Statistics from Khulna University, Bangladesh. He is an independent researcher in the Statistics Department of Khulna University, Bangladesh. During his master's program, his thesis title was 'Fear of Falling and Its Relationship to Depression and Loneliness among the Elderly'. He was involved with different public health projects in various national and international organizations, including the International Centre for Diarrhoeal Disease Research, Bangladesh; Unicef; Cornell University, USA; Khulna University, Bangladesh and iDE PROSHAR funded by USAID. Mr. Rahman has published 15 articles in different scholarly journals. His main research interests include the areas of public health and geriatric mental health. 